\title{
Heat Waves: Health Effects, Observed Trends and Climate Change
}

\author{
Martínez-Austria Polioptro F and Bandala Erick R.
}

Additional information is available at the end of the chapter

http://dx.doi.org/10.5772/intechopen.75559

\begin{abstract}
According to climate change scenarios, the average annual temperature will increase by around $4^{\circ} \mathrm{C}$ if current trends continue. Maximum temperatures, however, have already registered higher values in different regions of the world, increasing the number, duration and intensity of heat waves. With the increase of maximum temperatures and the increase of significance of heat wave events, reports of mortality episodes due to heat effects have been increasing. According to the information from the Centre for Research on Epidemiology of Disasters (CRED), 5 of the 20 deadliest disasters between 1996 and 2015 were heat wave events. This chapter analyzes heat wave events, the criteria for determining dangerous temperature thresholds, as well as trends already observed, and those expected due to climate change. Heat wave events are correlated with observed increases on mortality rates, and recommendations are suggested to prevent their effects on human health.
\end{abstract}

Keywords: maximum temperatures, heat waves, heat and health, heat waves and climate change, heat wave mortality

\section{Introduction}

The number and cost of natural disasters related to climate have increased significantly in recent decades. Goklany [1] elaborated a study of the annual average number of climaterelated extreme events, recorded per decade, during 1900-2008. He found a highly remarkable growth since the middle of the twentieth century; while 23 weather extreme disasters were observed in 1950-1959, and 354 were recorded only for the first decade of twenty-first century, until 2008. 
According to Hoeppe [2], the number of events that caused human or material losses triplicated from 300 in 1980 to 900 in 2014. In fact, in the 2018 Global Risks Report of the World Economic Forum, the risk of extreme weather events shows the most unfavorable combination of impact and probability of occurrence, which poses the greatest global risk to humanity nowadays [3].

Heat wave events have become a major concern, mainly due to their effects on human health. According to the World Meteorological Organization (WMO), the number of casualties due to extreme temperature grew 2300\% between 1991 and 2000 and 2001-2010 [4] being, by far, the greatest growing rate among climate-related disasters. This pervasive trend of heat wave events keeps going. For instance, the Centre for Research on Epidemiology of Disasters (CRED) have reported that 4 of the 10 deadliest disasters in 2015 were heat wave events [5] in agreement with one of the key findings of the Intergovernmental Panel for Climate Change (IPCC) Fifth Assessment Report saying that "changes in many extreme weather and climate events have been observed since about 1950. Some of these changes have been linked to human influences, including a decrease in cold temperature extremes, an increase in warm temperature extremes ..." [6].

In the last few decades, records of particularly dangerous heat wave events causing several deaths, even in developed countries with good public health services, have been reported. For example, the heat wave at Chicago in July, 1995 causing 514 heat-related deaths [7], the extreme heat of 2003 in Europe, affecting mainly France, with almost 15,000 deaths [8] and the one at the Russian Federation in 2010, which caused 55,736 deaths [9].

Climate change is expected to increase the average temperature as well as the probability of extreme climate, including heat wave events [10-12]. Moreover, the best climate data estimates coming from the general circulation models are for average temperatures, making uncertainty in extreme temperatures and heat wave events much greater [13]. Predictions of temperature increases are based on results from the general circulation models. In this sense, the IPCC has estimated the performance of these models by comparing their results with climate parameters observed during 1980-1999. For temperature, once the multimodel results (the average of 23 general circulation models) have been analyzed, the estimated error (the difference between observed and modeled data) is rarely higher than $2^{\circ} \mathrm{C}$, even though the individual models may show errors of up to $3^{\circ} \mathrm{C}[14]$. Nevertheless, the IPCC has pointed out that large-scale trends are simulated with higher accuracy than regional ones. Therefore, the analysis of the vulnerability to and effects of climate change, at local or regional levels, must be based on observed evidence. Hence, local trend analysis is crucial for the analysis of heat wave events. Another reason, probably more important, for local analysis of heat wave events and extreme temperatures is that its effects on human health depend to a large extent on the level of acclimatization of the local population, which includes not only physiological aspects, but others like practices of prevention, transportation patterns, age and/or type of constructed environment (i.e. [8, 15]).

Heat wave events have not been sufficiently considered by most governments, while more attention and resources paid to other phenomena with greater public visibility, such as floods or severe storms, for example. Usually, the population is also not fully aware of the risk posed 
by extreme heat events. Therefore, any effort that spread heat wave events relevance, helps to mobilize governments, social organizations and individuals towards better prevention and a greater aware is of great importance; before, during and after a heat wave event.

\section{Heat wave events: definition and thresholds}

A heat wave is a period, usually lasting several days, with temperatures significantly higher than average or maximum values observed in the past during the same dates. The importance of extreme temperatures, and hence of heat wave events, becomes more significant when it affects human health. However, because the health-related effects of temperature depend on local factors - such as population acclimatization, age or health precondition - and other meteorological variables - such as humidity and wind speed - dozens of indices to determine the risk threshold of a heat wave have been reported. For instance, Smith et al. [16] listed 16 indices used in the United States.

A group of indices suggests the use of apparent temperature, which is calculated as a function of the observed temperature and relative humidity. The best known of them has been recommended by the US National Oceanographic Administration (NOAA), where the apparent heat index is calculated with the following equation:

$$
\begin{aligned}
& H_{i}=-42.379+2.049 T+10.14 R-0.224 T R-6.83 \times \\
& 10^{-3} T^{2}-5.48 \times 10^{-2} R^{2}+1.22 \times 10^{-3} T^{2} R+8.52 \times \\
& 10^{-4} T R^{2}-1.99 \times 10^{-6} T^{2} R^{2}
\end{aligned}
$$

where $H_{i}$ is the apparent temperature, $R$ is the relative humidity and $T$ is the ambient temperature $\left({ }^{\circ} \mathrm{F}\right)$. A $H_{i}$ of $124^{\circ} \mathrm{F}$ or higher is considered very dangerous.

The main drawback of the heat index is related with the lack of access to relative humidity information. Recently, an extensive analysis to compare different heat indices with the registered health effects was carried out [17]. These authors found that simple indices based solely on temperature may be the most applicable for use in alert systems, but that all the corresponding temperature thresholds should be considered for regional analysis. Another group of threshold criteria establishes an absolute boundary to declare a heat wave, which is a specific value of the maximum temperature. So, for example, in the United Kingdom, the Met Office National Severe Weather Service (NSWSS) establishes a regional system with a threshold of maximum day and night temperatures, as shown in Table 1. In Mexico, a threshold for heat wave events in Mexico City has been proposed [18] as a maximum observed temperature greater than or equal to $30^{\circ} \mathrm{C}$ for three or more consecutive days, with an observed average temperature of $24^{\circ} \mathrm{C}$. These authors suggested that, to determine the absolute temperature limits used in these criteria, it is necessary to identify the temperature where the mortality increases over average values and can be attributed to heat waves.

A second group of thresholds is defined by statistical analysis, usually selecting some temperature value percentile as the upper boundary. Some indices use the average daily 


\begin{tabular}{lll}
\hline NSWWS Region & Temperature, ${ }^{\circ} \mathbf{C}$ & \\
\cline { 2 - 3 } & Day & Night \\
\hline London & 32 & 18 \\
South East & 31 & 16 \\
South West & 30 & 15 \\
Eastern & 30 & 15 \\
West Midlands & 30 & 15 \\
East Midlands & 30 & 15 \\
North West & 30 & 15 \\
Yorkshire and Humber & 29 & 15 \\
North East & 28 & 15 \\
\hline
\end{tabular}

Table 1. Threshold maximum day and night temperatures defined by NSWSS [19].

temperature as reference temperature, while others-most of them-use maximum temperature values. As for extreme temperature events duration, some indices consider a heat wave when temperature exceeds the threshold limit during two or more days, while others estimate a heat wave occurs when the limit is exceeded in a single day.

The WMO Task Team on Definition of Extreme Weather and Climate Events encourages the report of the number of days in a month above percentile 90th [20]. In France, after the heat wave in 2003, a warning system was defined with an index based on the maximum and minimum temperatures, on average of 3 days, applicable to 96 cities of that country, based on studies in 14 pilot cities. Limits were determined by studying excess mortality caused by extreme heat, and the 98th percentile temperature value was used in the 2004 warning system. Subsequently, in 2005, the limits were updated for some cities, based on a more detailed analysis, and adopting the 99.5th temperature value percentile as the threshold. The resulting limits rank from 18 to $36^{\circ} \mathrm{C}$ for Lille to 21 to $36^{\circ} \mathrm{C}$ for Toulouse [21-23].

The methodology used in the warning systems of the United Kingdom and France, based on local studies - by city or region - for the relationship between temperature and excess mortality is interesting. Nevertheless, mortality information may not be available or the costs of these studies may not be suitable to many communities, and protecting the population through warning systems remains necessary. In these cases, it is advisable to use a boundary based only on maximum temperatures, with a conservative threshold used in national or international experience, for example, the 90th percentile, while the detailed studies are conducted.

It is worth to note that differences between definitions of heat wave events used in different countries represent a limitation to elaborate comparative analysis on the phenomenon between different regions of the planet. 


\section{Heat waves, morbidity and mortality}

Extreme heat and effects on the population's health (higher morbidity and mortality) have been consistently reported in the last few decades [24-26]. As climate change effects become more significant, understanding and taking actions that may help to prevent heat-related health effects in the exposed population is an imperative topic that worth effort [27] in order to identify major trends, and vulnerable subpopulations since the frequency of these type of events is expected to increase in the near future [28, 29]. Some regions are expected to experience more intense, frequent and long-lasting extreme heat events by the second half of the twenty-first century with the corresponding health consequences.

While the scientific community remains discussing the best definition of a heat wave, such extreme weather-related events have continuously produced notable impact on human mortality, regional economies and ecosystems [29]. When the consequences of climate change are considered, warmer climate is expected to generate more intense, longer lasting and frequent heat waves contributing not only to human mortality but causing economic impacts, inconvenience and discomfort. The threat posed by extreme heat in a society not properly prepared to respond to weather-related events is significant considering that heat waves are 3 of the 10 worst natural disaster-related to the number of deaths recorded in 2013 [30].

Climate change sensitive areas are of particular concern mainly related with the effect of heat wave episodes on most vulnerable population subgroups such as children, the elderly, outdoor workers or inhabitants of urban areas [31]. Extreme heat events already account for the highest number of annual fatalities in the United States, and the annual number of heat waves has been found increasing for the average US city with increased length and intensity. Just to mention an example, Southwestern United States is a region of particular interest because it is predicted with increased average temperature and probability of extreme climate events, particularly in the second half of this century, based on results from general circulation models [32]. Among the different consequences, effects on population resulting of exposure to extreme heat range from dehydration, heat exhaustion, deadly heatstroke, kidney problems, lethargy and death; along with other side effects such as poor work attendance and/or performance among the exposed population.

In general, according to IPCC, regions in the middle and high latitudes will experience the highest temperature increases in the course of this century with a mean global temperature expected up to $4^{\circ} \mathrm{C}$ [6], based on the results of general circulation models. They have noticed, however, that large-scale features of climate are simulated with more accuracy that regional- and smallscale features, identifying the need of improved models capable of considering not only that changes in extreme events are not evenly distributed in space but characterized by particular patterns related to larger scale climate changes. Several of these places are projected also having the largest increase in population over the next decade and a significant increase in the frequency, last and intensity of extreme heat events [31] putting people and businesses at risk to the impacts of climate-related hazards. Figure 1 shows the rising heat wave trends in the large US cities as an example of the overall tendency related with heat waves all around the world [32]. 

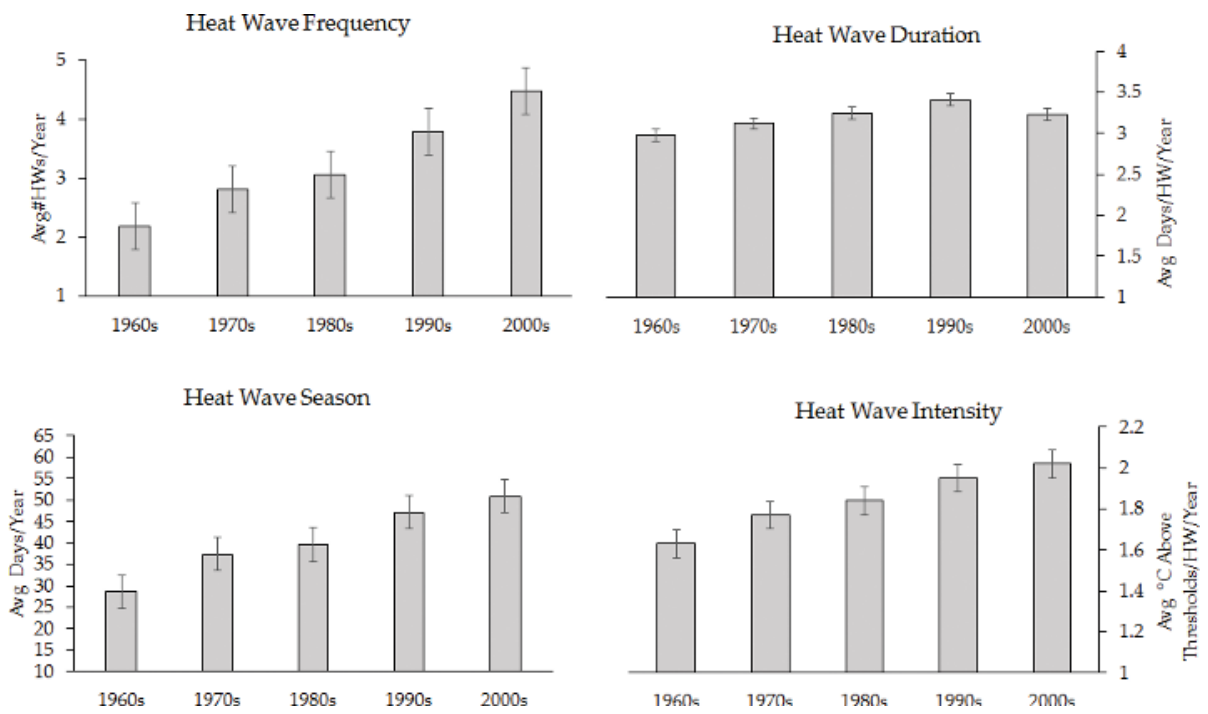

Figure 1. Decadal average trend for different heat wave characteristics across 50 US cities [32].

As shown, intensity on heat waves trends to increase as the frequency and heat wave season from the 1960s to 2000s, and only a slight decrease was identified for the duration of every heat wave event in the same period. The authors found the magnitude of the chance of the first three characteristics being rising by over $5 \%$ with the frequency of the heat wave increasing $20 \%$ per decade, generating undesirable effects on the population.

High body temperature is usually related with increase in heart and respiratory rate and, when reaching extreme values, also with brain, heart, lungs, kidney and liver damage. All these body responses to extreme heat can hardly be ignored, generating people to visit emergency rooms at hospitals and a significant amount of deaths every year. For example, only in the United States, more than 7400 people died from heat-related causes during 1999-2010 and over 65,000 visited emergency rooms each year $[33,34]$.

Table 2 shows the count of heat-health events accounted in California, USA between 2000 and 2009, including the excess hospitalization count and quantile. As shown, the count of excess hospitalization occurring statewide ranks as high as the frequency of heat wave event increases probably due to the exhaustion generated for the extreme heat events in the population organism [28].

Nevertheless, the trend in increasing the number of people suffering of heat-related effects is not privative of a specific location as suggested recently in a work where the temporal variation in heat-mortality associations in multi-country data set was assessed [35]. These authors found a significant prevalence of heat-related death in the studied period for the seven countries included in their study as shown in Table 3. Nevertheless, they found a decrease in the heatrelated mortality risk in most of the countries analyzed and, in some cases, completely abated. 


\begin{tabular}{|c|c|c|c|c|}
\hline Year & Event span & Peak date & Duration, days & Excess hospitalizations \\
\hline \multirow[t]{3}{*}{2000} & May 18-24 & May 21 & 7 & 217 \\
\hline & Jun $12-16$ & June 14 & 5 & 299 \\
\hline & Sept 5-9 & Sept 7 & 5 & 700 \\
\hline \multirow[t]{2}{*}{2001} & May 2-11 & May 8 & 10 & 959 \\
\hline & May 29-Jun 1 & May 31 & 4 & 460 \\
\hline 2002 & Jun $7-13$ & Jul 9 & 7 & 848 \\
\hline \multirow[t]{6}{*}{2003} & May 19-22 & May 20 & 4 & 845 \\
\hline & May 27-29 & May 28 & 3 & 454 \\
\hline & Jun 24-30 & Jun 27 & 7 & 717 \\
\hline & Jul 8-22 & Jul 14 & 15 & 1063 \\
\hline & Sept $10-15$ & Sept 13 & 6 & 629 \\
\hline & Sept $17-23$ & Sept 22 & 7 & 839 \\
\hline 2004 & Sept $1-17$ & Sept 7 & 17 & 1657 \\
\hline \multirow[t]{2}{*}{2006} & Jul 7-9 & Jul 8 & 3 & 367 \\
\hline & Jul 13-26 & Jul 23 & 14 & 1254 \\
\hline 2007 & May 6-9 & May 7 & 4 & 327 \\
\hline 2008 & May $13-18$ & May 16 & 6 & 903 \\
\hline \multirow[t]{2}{*}{2009} & May $15-18$ & May 17 & 4 & 160 \\
\hline & Aug 7-17 & Aug 10 & 11 & 228 \\
\hline
\end{tabular}

Table 2. Heat-health events in California, US in 2000-2009 (taken from [28]).

\begin{tabular}{llllll}
\hline Country & Total deaths & Period & \multicolumn{3}{l}{ Summer temperature, ${ }^{\circ} \mathrm{C}$} \\
\cline { 5 - 6 } & & & Minimum & Median & Maximum \\
\hline Australia & 361,135 & $1988-1998$ & 14.5 & 21.6 & 32.2 \\
& & $1999-2009$ & 14.8 & 22.1 & 32.7 \\
Canada & 679,693 & $1986-1998$ & 3.9 & 17.4 & 28.0 \\
& & $1999-2011$ & 4.4 & 17.7 & 28.5 \\
Japan & $8,117,084$ & $1985-1998$ & 14.9 & 24.3 & 31.7 \\
South Korea & $199-2012$ & 15.3 & 25.1 & 31.6 \\
& & $1992-2001$ & 14.9 & 23.7 & 31.8 \\
Spain & 530,618 & $2002-2010$ & 14.5 & 23.6 & 30.5 \\
& $1,050,433$ & $1990-2000$ & 12.4 & 22.2 & 31.1
\end{tabular}




\begin{tabular}{llllll}
\hline Country & Total deaths & Period & \multicolumn{3}{l}{ Summer temperature, ${ }^{\circ} \mathrm{C}$} \\
\cline { 3 - 5 } & & & Minimum & Median & Maximum \\
\hline UK & $2,285,519$ & $1993-1999$ & 8.5 & 15.3 & 24.3 \\
& & $2000-2006$ & 11.1 & 23.6 & 31.8 \\
USA & $1985-1995$ & 11.1 & 23.6 & 31.8 \\
& & $1996-2006$ & 11.7 & 23.6 & 31.9 \\
\hline
\end{tabular}

Table 3. Heat-related deaths in seven countries during the last two decades (taken from [35]).

Despite the controversial results, it is clear that exposure to extreme heat poses a significant threat to human health, mainly when pre-existing health conditions are present. The lack of information on the source of the risk or the physiologic response generated by extreme heat in the different individuals has been identified as a major gap in knowledge that worth to be filled [36] as well as the considerations for the proper diagnose of the heat-related effects on health.

\section{Observed trends and climate change}

The maximum temperature has shown a growing trend in recent decades. WMO has reported a steady increase in the number of countries reporting new maximum temperature records. As shown in Figure 2, while less than 10\% of the countries reported new temperature records in 1961-1970, 44\% (56 countries) reported new maximum temperature in 2001-2010 [4].

Most climate change publications have focused on average temperature values. However, a slight increase in the average temperature means, in a changing climate, a greater increase in maximum temperature values. Moreover, it can happen that average temperature does not change or even decrease while the maximum temperatures increase significantly. The explanation of this phenomenon is found in the possible changes in temperature distribution of probabilities, as indicated by the IPCC (see Figure 3). Changes in the average temperature can

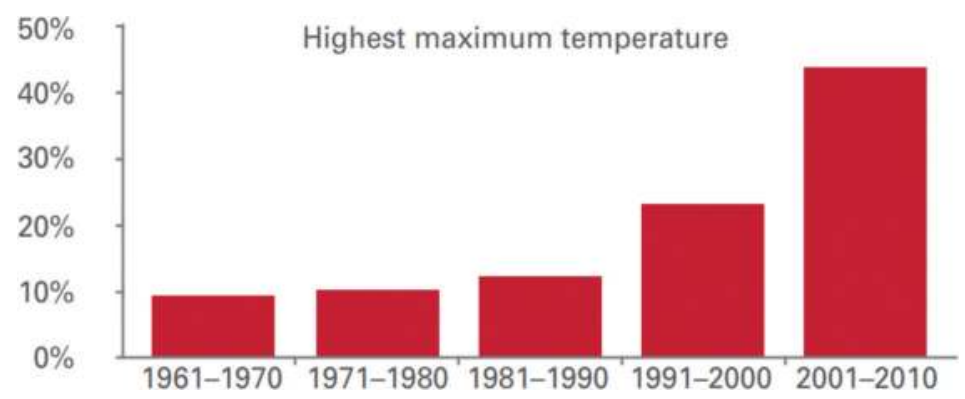

Figure 2. Absolute country records of the daily maximum temperature [4]. 

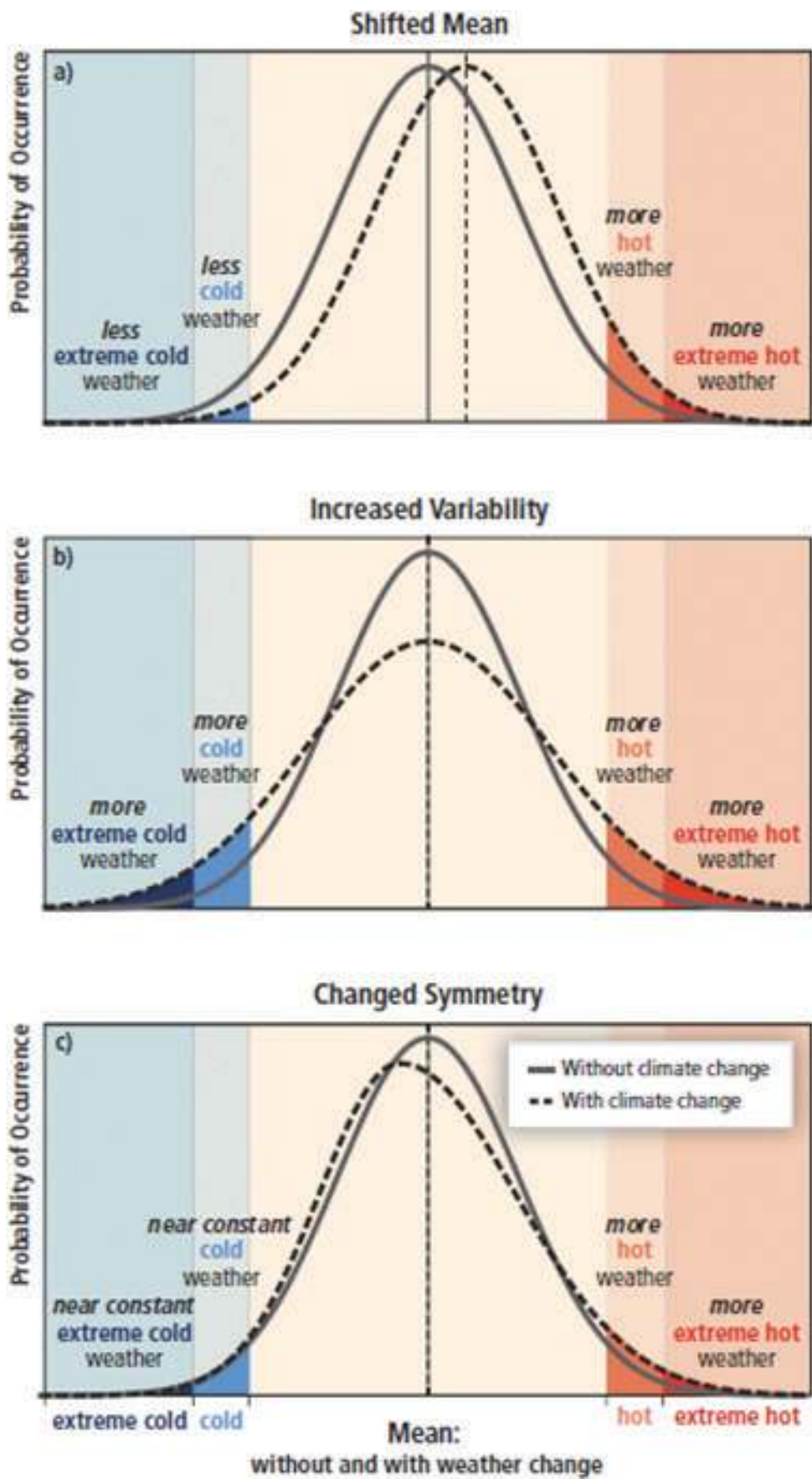

Figure 3. Effect of changes in temperature distribution extremes [37]. 
be produced, with a shift in the probability distribution toward areas of higher temperature (Figure 3a). An increase in variability may also occur, with more extreme temperaturesboth, cold and heat (Figure $3 \mathbf{b}$ )-or changes in the distribution symmetry with decrease in average temperature and increase in temperature at both extremes (Figure 3c).

To illustrate this phenomenon, Figure 4 shows the observed variation of minimum, medium and maximum temperatures in Mexicali (Northwestern Mexico) where an analysis on average temperature would indicate that the climatic change direction is to decrease, although in fact, it warms up and is increasingly higher for both diurnal and nocturnal values. Because minimum temperatures increase faster than maximum temperatures, average temperature value seems to decrease. In this case, changes in the symmetry of distribution probabilities are assumed. Therefore, the study of heat wave trends should be based mainly on maximum and minimum temperature analysis rather than average temperature values.

The IPCC special report on the risk of extreme events clearly states that "is very likely that there has been an overall decrease in the number of cold days and nights, and an overall increase in the number of warm days and nights" [37]. On the other hand, the magnitude of the change in the extreme temperatures depends on the region. There is sufficient evidence of significant increases in maximum temperatures, day and night, in North America, Europe and Australia. For the rest of the regions, it is necessary to consider the lack of data and detailed studies before a conclusion can be stated.

In the United States, a detailed study showed that in most of the continental territory, there is a positive trend in temperature for 1979-2011 with a level of significance greater than 95\% in the Mann Kendall test [16]. These authors indicate that the regions of the United Sates with the greatest positive tendency are found in the Southeast and the Great Plains. These results are complemented by a study in the Southeastern United States and Northwest Mexico-the

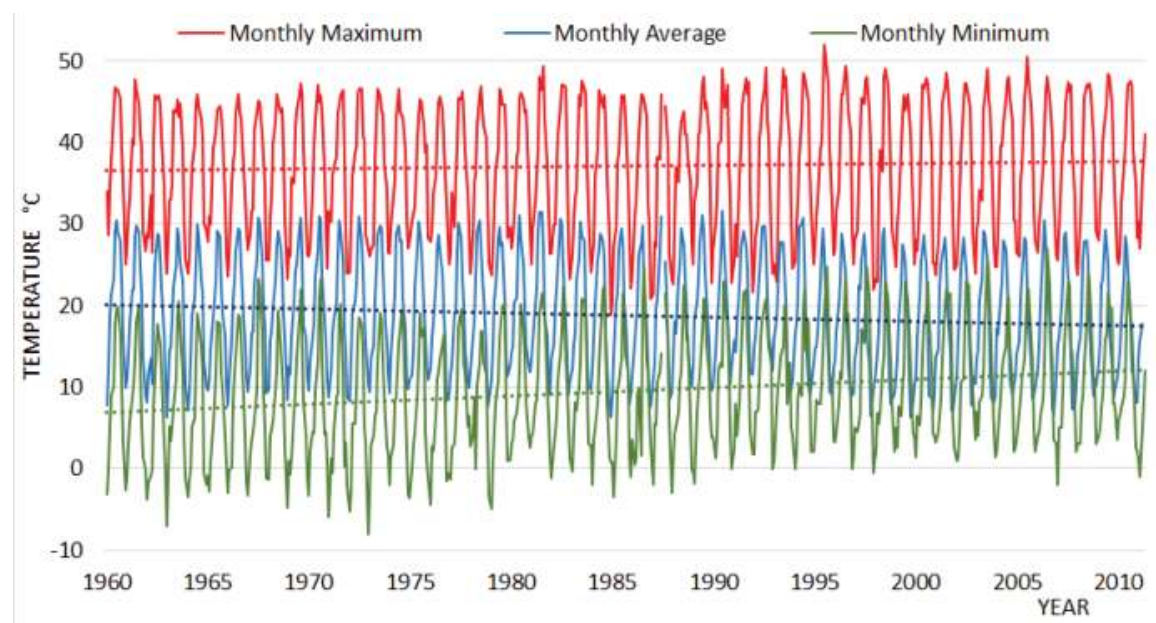

Figure 4. Maximum, average and minimum temperature trends observed in Mexicali, Mexico. 
Sonoran and Mojave Desert-where a positive trend, using the Spearman's Rho test, during 1960-2010 in maximum temperatures of Tucson and Phoenix in the United States and Obregon City and Mexicali in Mexico was found [31]. As shown in Figure 5, there is a clear trend of increase in maximum temperatures throughout the region, clearly seen by comparing against average temperature over the analyzed time interval. During 2005-2010, the maximum temperature in Ciudad Obregon was $2.96^{\circ} \mathrm{C}$ higher than $1961-1965,2.76^{\circ} \mathrm{C}$ higher in Phoenix, $2.52^{\circ} \mathrm{C}$ higher in Tucson, $2.3^{\circ} \mathrm{C}$ higher in Morelos Dam, $2.06^{\circ} \mathrm{C}$ higher in Mexicali and $1.34^{\circ} \mathrm{C}$ higher in Las Vegas. The number of days that exceeds the 90 th maximum temperature percentile were found also growing fast, as shown in Figure 6.

Europe has been subject to exceptional heat wave events. The 2003 heat wave in Europe, widely documented, caused more than 33,000 deaths, and extended with record temperatures in the range of 35 to $>40^{\circ} \mathrm{C}$, from Portugal and England to Turkey [38]. France, the most affected country, reported more than 14,000 deaths [8]. During the 2010 heat wave in the Russian Federation, which caused more than 55,000 deaths, the temperature anomaly in Moscow was as high of $+18^{\circ} \mathrm{C}$ in July [39]. In the United Kingdom, a definite trend in the increase of moderate heat wave events, both in number and duration, while the trends for extreme heat wave events are still unclear [40].

Australia is one of the countries that suffers most due to heat wave events. A report from the Australian Climate Council has found a notable increase in the magnitude, duration and frequency of heat waves. It has been found, for example, that in the last 50 years, the number

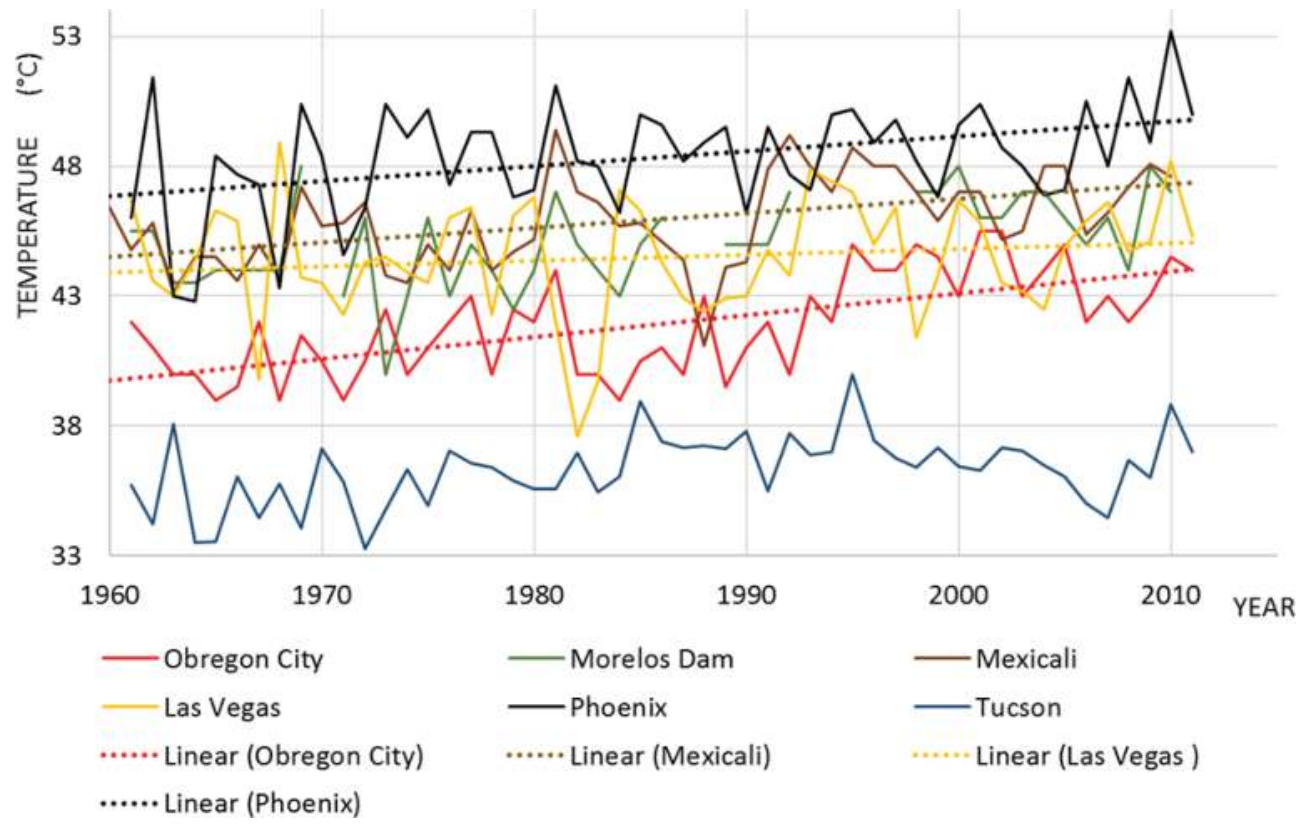

Figure 5. Maximum monthly temperatures and linear trends for the Sonoran Mojave Desert region for the month August [31]. 


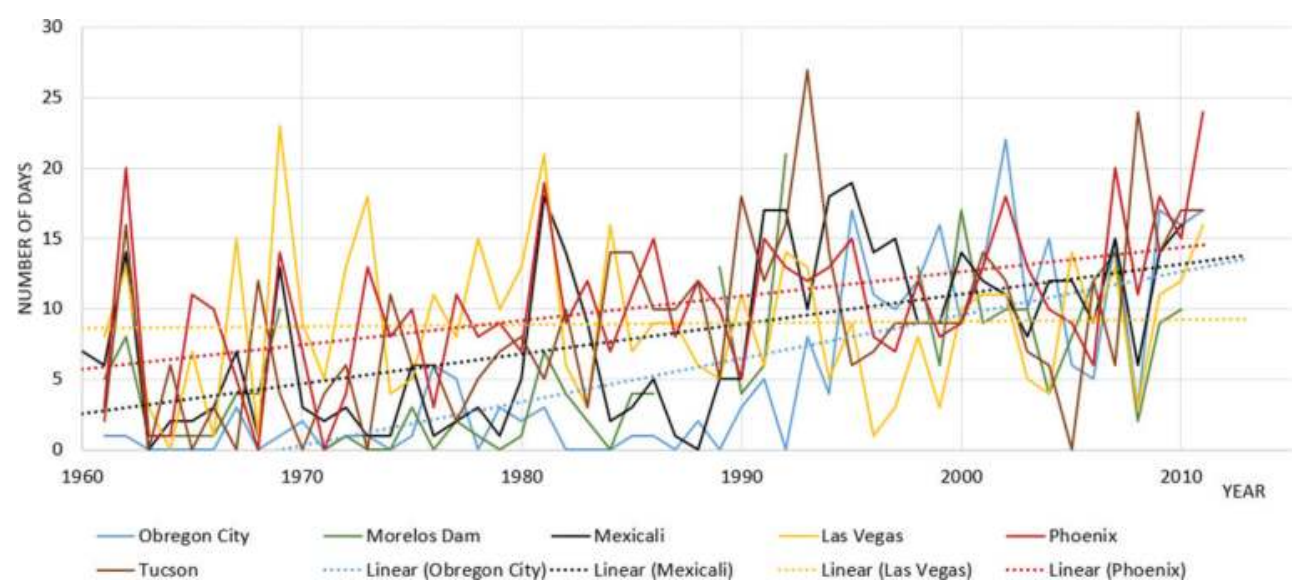

Figure 6. Number of days that exceeded the 90th percentile of average maximum temperatures in August, in the Sonoran Mojave Desert region [31].

of hot days in Australia has doubled and that "in the last hundred years, heat waves have caused more deaths than any other natural risk" [41]. Trend analyzes conducted so far show an increase in heat wave events' intensity, duration and frequency [42].

There are reports from many other regions of the world, which report the same growing trends in the number and duration of heat waves [43-45]. However, it is essential to emphasize the remaining lack of information and analysis in large areas, for example, at Central America, South America and Africa.

The trends observed in extreme heat and heat wave events, unfortunately, are in the direction predicted by climate change scenarios. Indeed, the Fifth Report of the IPCC indicates that during the twenty-first century, "it is very likely that heat waves will occur more often and last longer" [6]. The special report on extreme events of the IPCC is even more conclusive, and states that "it is virtually certain that increases in the frequency and magnitude of warm daily temperature extremes and decreases in cold extremes will occur in the twenty-first century at global scale" [37]. The magnitude of these events at the regional level, however, will depend on local variables such as elevation, synoptic effects, the occurrence of anticyclones, and so on, which is why more precise modeling at smaller scales is essential as well as their calibration according to the changes will develop over time.

For Europe, the results of a simulation model for the twenty-first century, with a mesh resolution of $50 \mathrm{~km}$ were recently published [46]. The report shows a highly significant increase in the number of days with heat wave events per year, the maximum average temperature and the frequency. From the trends in their report, the number of heat wave events per year will increase approximately, during 2000-2100, from 1 to 2.5 in Western Russia, from 10 to 27 in Eastern Europe and from 1 to almost 2.5 in Western Europe. The mean maximum temperature, in the same period, will grow from 19 to $>24^{\circ} \mathrm{C}$ in Western Russia, from 20 to almost $26^{\circ} \mathrm{C}$ in Eastern Europe and from around 18 to $>24^{\circ} \mathrm{C}$ in Western Europe [46]. 


\begin{tabular}{|c|c|c|c|c|c|c|c|c|c|c|}
\hline & \multicolumn{2}{|c|}{ Northern Europe } & \multicolumn{2}{|c|}{ Eastern Europe } & \multicolumn{2}{|c|}{ Central Europe } & \multicolumn{2}{|c|}{ Western Europe } & \multicolumn{2}{|c|}{ Southern Europe } \\
\hline & $\begin{array}{l}1981- \\
2000\end{array}$ & $\begin{array}{l}2071- \\
2100\end{array}$ & $\begin{array}{l}1981- \\
2000\end{array}$ & $\begin{array}{l}2071- \\
2100\end{array}$ & $\begin{array}{l}1981- \\
2000\end{array}$ & $\begin{array}{l}2071- \\
2100\end{array}$ & $\begin{array}{l}1981- \\
2000\end{array}$ & $\begin{array}{l}2071- \\
2100\end{array}$ & 1981-2000 & $2071-2100$ \\
\hline Deaths & 0.98 & 27.24 & 4.81 & 177.6 & 61.51 & 2305.77 & 34.33 & 1022.67 & 105.77 & 7019.99 \\
\hline \multicolumn{11}{|l|}{$/ 10^{7}$ inhabitants } \\
\hline $\begin{array}{l}\text { Exposed } \\
\text { population } / 10^{6} \\
\text { inhabitants }\end{array}$ & 9618 & 269,167 & 9989 & 341,025 & 9932 & 322,309 & 9993 & 298,558 & 9828 & 634,474 \\
\hline
\end{tabular}

Table 4. Prognosis of people affected and deaths in Europe by heat waves (with data from [47]).

Forzieri et al. [47] analyzed the impacts on the European population due to climate change, in a period of 30 years. With respect to heat waves, Table 4 presents their results of the changes in exposed population and expected deaths during 1981-2000 and 2071-2100.

For the United States, Kunkel et al. [48] estimated, for heat wave events in summer, that the annual 3-day heat wave temperature increased by $3-8^{\circ} \mathrm{C}$ and the number of heat wave days from 30 to 60 days per year. The analysis for other regions and countries also coincides in forecasting a growth of heat waves during the twenty-first century. For example, the study by Meehl and Tebaldi [29] can be cited who consider North America and Europe; the report by Steffen et al. [41] for Australia; another by Dutta and Chrsiya [49], focused on the effects on health due to climate change in India; or the projections of extreme heat performed by Salinas-Prieto et al. [50] for Mexico, forecasting increases between 4.6 and $5.8^{\circ} \mathrm{C}$ in maximum temperatures for northern Mexico during 2075-2099, using the RCP8.5 Scenario. Even since there is a consensus on the increase in intensity, frequency and duration of heat wave events due to climate change, there is still a great uncertainty about its magnitude at regional scale, so the study of the observed trends should be continued, and carried out where the information or analysis capabilities have not allowed it until now.

\section{Concluding remarks}

It seems evident that extreme heat, resulting from climate change, poses a significant treat not only for people's health, but also in general for achieving the Millennium Sustainable Development Goals proposed by the UN by being within the top dangerous climate-related disasters with the greatest gap in knowledge.

The lack of consensus on the definition and threshold values for heat wave events among the scientific community is beyond the academic work as it may become a life or death issue for vulnerable population segments or regions. As a result, the urge for generating more reliable information and used for decision making becomes with a higher significance as the time goes by.

The relationship among extreme heat during heat wave events and the amount of deaths or the increase of people visiting emergency room in hospitals is undeniable, but the scientific 
work reported nowadays does not suffice to figure out what consequences may occur in other regions where climate variability is barely known or completely unknown. The need for more studies is clear, and additional resources to be invested in such sensitive knowledge areas seem mandatory in order to avoid potential catastrophic scenarios in the forthcoming years.

\section{Author details}

Martínez-Austria Polioptro $\mathrm{F}^{1 *}$ and Bandala Erick R. ${ }^{2}$

*Address all correspondence to: polioptro.martinez@udlap.mx

1 UNESCO Chair on Hydrometeorological Risks, University of the Americas Puebla, Mexico

2 Division on Hydrological Sciences, Desert Research Institute, Las Vegas, Nevada, U.S.A.

\section{References}

[1] Goklany IM. Deaths and death rates from extreme weather events: 1900-2008. Journal of American Physicians and Surgeons. 2009;14(4):102-109

[2] Hoeppe P. Trends in weather related disasters -consequences for insurers and society. Weather and Climate Extremes. 2016;11:70-79

[3] World Economic Forum. The global risks report 2018, 13th ed. Geneva: World Economic Forum; 2018

[4] World Meteorological Organization, The Global Climate 2001-2010. A Decade of Climate Extremes. Summary Report. Geneva, Switzerland, 2013

[5] Guha-Sapir D, Hoyois P, Below R. Annual Disaster Statistical Review 2015. The numbers and Trends. CRED, Brussels, 2016

[6] IPCC, Climate Change 2014. Synthesis Report. Intergovernmental Panel of Climate Change. Oxford; 2014

[7] Withman S, Good S, Donoghue ER, Benbow N, Shou W, Mou S. Mortality in Chicago attributed to the July 1995 heat wave. American Journal of Public Health. 1997;87(9):1515-1518

[8] Kovats RS, Ebi KL. Heatwaves and public health in Europe. European Journal of Public Health. 2006;16(6):592-599

[9] World Meteorological Organization. Atlas of mortality and economic losses from weather, climate and water extremes (1970-2012). Geneva. 2014

[10] IPCC, Summary for Policymakers. In Climate Change 2013: The Physical Basis. Stocker TF, editor. Cambridge: Cambridge University Press; 2013

[11] Meehl GA, Tebaldi C. More intense, more frequent, and longer lasting heat waves in the 21st century. Science Reports. 13 August 2004;305:994-997 
[12] Hughes L, Perkins S. Heatwaves: Hotter, longer, more Often. Sydney, Australia: Climate Council of Australia; 2014. p. 62

[13] Ganguly AR, Steinhaeuser K, Erickson DJ, Branstetter M, Parish ES, Singh N, Drake JB, Lawrence B. Higher trends but larger uncertainty and geographic variability in 21st century temperature and heat waves. PNAS. 2009;106(37):15555-15559

[14] Randall DA, Word RA. Climate models and their evaluation. In: IPCC, Climate 2007: Impacts, Adaptation and Vulnerability. Cambridge: Cambridge University Press; 2007. pp. 589-662

[15] World Meteorological Organization and World Health Organization, Heatwaves and Health. Guidance on Warning-System Development, Vols. WMO-No. 1142, McGregor GR. ed, Geneva Switzerland, 2015

[16] Smith TT, Zaitchik BF, Dohlkr JM. Heat waves in the United States: Definitions, patterns and trends. Climatic Change. 2013;118(3-4):811-825

[17] Kent ST, McClour LA, Zaitchik BF, Smith TT, Gohlke JM. Heath waves and health outcomes in Alabama (USA); the importance of heat wave definition. Environmental Health Perspectives. 2104;122(2):151-158

[18] Jáuregui E. The heat spells of Mexico City. Investigaciones Geográficas. 2009;70:71-76

[19] Public Health England, Heatwave Plan for England. London: NHS England2015

[20] WMO Task Team on Definition of Extreme Weather and Climate Events, Meeting Report 26-26 February. WMO, 2014

[21] Wagner V, Le Tertre A, Laaidi K. French heat health warning system: Validation of temperature thresholds. Institute de veille Sanitaire; 2006

[22] Pascal M, Laaldi K, Ledrans M, Baffert E, Caserlo-Sconemann C, Le Tertre A, Manach J, Medina S, Rudant J, Empereur-Bissonnet P. France's heat health watch warning system. International Journal of Biometeorology. 2006;50(3):144-153

[23] Laadi K, Ung A, Wagner V, Buaudeau P, Pascal M. The French Heat and Health Watch Warning System: Principles, Fundamentals and Assessment. Institute de veille sanitaire; 2013

[24] Kingsley S, Eliot M, Gold J, Vanderslice R, Wellenius G. Current and projected heatrelated morbidity and mortality in Rhode Island. Environmental Health Perspectives. 2016;124(4)

[25] Basu R, Samet J. Relation between elevated ambient temperature and mortality: A review of the epidemiologic evidence. Epidemiologic Review. Vol. 24. 2002

[26] Petkova E, Gasparrini A, Kineey P. Heat and mortality in New York City since the beginning of the 20th Century. Epidemiology. Vol. 25. 2014

[27] Gubernot D, Anderson G, Hunting K. Characterizing occupational heat-related mortality in the United States, 2000-2010: An analysis using the census of fatal occupational injuries database. American Journal of Industrial Medicine. 2015;58(8) 
[28] Guirguis K, Gershunov G, Tardy A, Basu R. The impact of recent heat waves on human health in California. Journal of Applied Meteorology and Climatology. 2014;53(1)

[29] Koppe C, Kovats S, Jendrotzky G, Menne B. Heat waves: Risks and responses. World Health Organization. Europe. Health and Global Environmental Change series, No.2. 2004

[30] Martinez-Austria P, Bandala E, Patino C. Temperature and heat waves trends in Northwest Mexico. Physics and Chemistry of the Earth. 2016;91:20-26

[31] Martinez-Austria P, Bandala E. Temperature and heat-related mortality trends in the Sonoran and Mojave Desert region. Atmosphere. 2017;8(3)

[32] Habeeb D, Vaego J, Stone B. Rising heat wave trends in large U.S. cities. Natural Hazards, Springer Netherlands. 2015;76

[33] Hess J, Saha S, Luber G. Summertime acute hear illness in U.S. emergency department from 2006 through 2010: Analysis of a nationally representative sample. Environmental Health Perspectives. 2014;122:1209-1215

[34] Xu J. Morbidity and Mortality Weekly Report: Quickstats Number of Heat-Related Deaths, by Sex-National Vital Statistical System, United States, 1999-2010. Atlanta, GA: Centers for Disease Control and Prevention; 2012

[35] Gasparrini A, Guo Y, Hashizume M, Kinney P, Petkova E, Lavinge E, Zanobetti A, Schwartz J, Tobias A, Leone M, Tong S, Honda Y, Kim H, Armstrong BG. Temporal variation on heat-mortality associations: A multicountry study. Environmental Health Perspectives. 2015;123(11):1200-1207

[36] Scott R. Between extremes: Health effect of heat and cold. Environmental Health Perspectives. 2015;11:A275-A280

[37] IPCC, Managing the Risks of Extreme Events and Disasters to Advance Climate Change Adaptation. Field C, Barros V, Stocker TF, Dahe Q. editors, New York: Cambridge University Press, 2012

[38] A. De Bono, P. Peduzzi, S. Kluser and G. Giuliani, Impacts of summer 2003 heat wave in Europe. United Nations Environment Programme, 2004

[39] Grumm RH. The central European and Russian heat event of July-august 2010. Bulletin American Meteorological Society. 2011;(October):1285-1296

[40] Sanderson MG, Economou T, Salmon KH, Jones SE. Historical Trends and Variability in Heat Waves in the United Kingdom. Atmosphere, no. September. 2017

[41] Steffen W, Hughes L, Perkins S. Heatwaves: Hotter, longer, more often. Melbourne: Climate Council of Australia; 2014

[42] Perkins-Kirkpatrick S, White C, Alexander L, Argüeso D, Boschat G, Cowan T, Evans J, Ekström M, Oliver E, Phatak A, Purich A. Natural hazards in Australia: Heatwaves. Climate Change, no. Special Issue on "The effect of historical and future climate changes on natural hazards in Australia". 2016 
[43] Arora M, Goel N, Singh P. Evaluation of temperature trends over India. Hydrological Sciences Journal. 2005;50(1):81-93

[44] Chaidez V, Dreano D, Agusti S, Duarte C, Hoteit I. Decadal trends in Red Sea maximum surface temperature. Nature-scientific reports. 2017;15(August)

[45] Schubert S, Wang H, Koster RD, Suárez MJ, Groisman PY. Northern Eurasian heat waves and droughts. American Meteorological Society. 2014:3169-3207

[46] Lau N, Nath MJ. Model simulation and projection of European heat waves in presentday and future climates. Journal of Climate. 2014;27(May):3713-3730

[47] Forzieri G, Cescatti A, Batista e Silva F, Feyen L. Increasing risk over time of weatherrelated hazards to the European population: a data-driven prognostic study. Lancet Planet health. 2017;1(August):e200-e208

[48] Kunkel KE, Liang X-Z, Zhu J. Regional climate model projections and uncertainties of U.S. summer heat waves. American Meteorological Society. 2010;23:4447-44458

[49] Dutta P, Chorsiya V. Scenario of climate change and human health in India. International Journal of Innovative Research and Development. 2013;2(8):157-160

[50] Salinas Prieto JA, Colorado Ruiz G, Maya Magaña ME. Climate Change Scenarios for Mexico (In Spanish), in Atlas de vulnerabilidad hídrica de México ante el cambio climático. Jiutepec, Morelos: Instituto Mexicano de Tecnología del Agua; 2015. pp. 41-70 
